\title{
HISTÓRIAS DE VIDA DE PROFESSORAS RURAIS: APONTAMENTOS SOBRE QUESTÕES HISTÓRICAS E POLÍTICAS DE FORMAÇÃO
}

\author{
Lúcia Gracia Ferreira *
}

\begin{abstract}
RESUMO
Este trabalho vincula-se à pesquisa realizada no campo dos estudos (auto)biográficos, com base nas histórias de vida de professoras rurais do município de Itapetinga (BA) que trabalharam no final do século XX e início do século XXI. A educação rural surgiu muito tarde e carrega no seu bojo marcas de sua (des)contextualização, implicando as políticas e práticas cotidianas e a ausência histórica de políticas vinculadas à formação. O texto intenta sistematizar e discutir histórias narradas por professoras, ao analisar questões concernentes ao cenário rural, de classe, de gênero, numa perspectiva histórica, com ênfase na feminização do magistério e no desenvolvimento do trabalho docente. Enfoca-se, de forma abreviada, aspectos teóricos relacionados à abordagem (auto)biografia, mediante utilização de narrativas de cinco professoras, numa perspectiva de colaboração, permitindo-nos pensar as histórias de vida, a formação e o desenvolvimento profissional, como marcados por dimensões históricas da professora rural e as respectivas influências e mudanças ocorridas no contexto de atuação.
\end{abstract}

Palavras-chave: Professores rurais. Escola rural. Histórias de vida. Formação docente.

\section{ABSTRACT \\ LIFE STORIES OF RURAL TEACHERS: NOTES ON HISTORICAL QUESTIONS AND TRAINING POLICIES}

The study integrates research conducted in the (auto) biographical field studies. It is based upon the lives of rural teachers in the city of Itapetinga, state of Bahia (Brazil), who worked in the late twentieth and early twenty-first century. Rural education came very late and is marked by its lack of contextualization concerning policies and daily practices as well as by the historical absence of policies related to training. The text aims to systematize and discuss stories told by teachers, to discuss matters pertaining to the rural context, class, and gender in historical perspective, emphasizing the feminization of teaching. We focus, shortly, upon theoretical aspects related to the (auto) biographical approach, through the use of narratives of five teachers. We work with them in a perspective of collaboration, allowing us to think about life stories, training and professional development, as marked by historical dimensions of the rural (female) teacher and about their influences and changes in their working context

Keywords: Rural Teachers. Rural School. Life stories. Teacher training

\footnotetext{
* Doutoranda em Educação pela Universidade Federal de São Carlos (UFSCar). Bolsista CNPq. Endereço para contato: Travessa Um, $\mathrm{n}^{\circ}$ 65, Nova Itapetinga, Itapetinga (BA). CEP: 45700-000. luciagferreira@hotmail.com
} 


\section{Introdução}

Este artigo apresenta um recorte de uma pesquisa sobre professoras da zona rural, ao discutir questões sobre formação, identidade, saberes e práticas docentes, no âmbito dos estudos (auto) biográficos, com base nas histórias de vida de professoras, centrando-se nos relatos de experiências de professoras que trabalharam no território rural do município de Itapetinga (BA), no final do século XX (anos 90) e início do século XXI, ao destacar diferenças/mudanças nessa localidade, melhorias e superações. Reconstruir histórias do território rural, sua cultura e suas relações com a escola permitenos identificar dimensões da própria profissão docente, com ênfase nas trajetórias de vida-formação das professoras que atuam no meio rural.

O texto intenta sistematizar e discutir histórias narradas por professoras, ao analisar questões vinculadas ao cenário rural, de classe, de gênero e profissionais de professoras no meio rural numa perspectiva histórica. A tessitura desse diálogo conta, primeiramente, com uma breve teorização sobre a educação rural e sua contextualização. Em seguida, situa-se a profissão docente e a professora rural na história e no contexto educacional brasileiro, discutindo-se brevemente sobre a profissão, questões de gênero, com ênfase na feminização do magistério e no desenvolvimento do trabalho docente. Por fim, serão discutidos aspectos teóricos relacionados à abordagem (auto) biografia e à pesquisa narrativa, mediante utilização de narrativas de cinco professoras, numa perspectiva de colaboração, permitindo-nos pensar as histórias de vida, a formação e o desenvolvimento profissional como marcados por dimensões históricas da professora rural e as respectivas influências e mudanças ocorridas no contexto de atuação.

\section{A educação rural: desafios e perspec- tivas}

A educação do meio rural refere-se à educação dos camponeses (PETTY; TOMBIM; VERA, 1981), configurando-se como uma educação surgida tardiamente, desvalorizada, mal vista e vinculada à lógica urbanocêntrica. $\mathrm{O}$ território rural já é cenário de muitas conquistas, as quais são fruto de reivindicações dos movimentos sociais, que possuem uma presença marcante. Destaca-se, nesse contexto, a ausência histórica de políticas vinculadas à formação de professores e a precariedade com que os professores desenvolvem o trabalho docente. Faz-se importante investir na formação dos profissionais que atuam no meio rural, formando-os para que conheçam a comunidade, o contexto em que vão atuar e os alunos com quem passarão tempos e tempos. É preciso maiores investimentos no meio rural, valorizando práticas de intervenção social, ofertando uma educação de qualidade e professores com formação acadêmica e conhecimentos condizentes com o contexto de atuação. Sobre essa questão, Silva (1952, p. 15) afirma que:

Educação é influência sistemática e com os objetivos definidos exercida sobre a criança, considerando-se todos os aspectos de sua personalidade. Educação rural, pois, consiste em orientar as populações das zonas rurais, no sentido da formação adequada ou conveniente às mesmas, vinculando-as ao meio $\mathrm{e}$ levando-as a reagir de modo eficiente sobre este.

A educação na sua dimensão social tem contribuído para o desenvolvimento de ações cidadãs e possibilitado aos sujeitos que habitam o meio rural construírem práticas de intervenção social e de dinamismo local. Também é válido dizer que o meio rural, pela sua representatividade, precisa ser visto pelas instâncias superiores, para que haja a implementação de políticas públicas buscando a valorização das pessoas do território rural e, entre outros, dos professores que lá atuam. O papel exercido pela escola no contexto rural destaca-se pela necessidade do desenvolvimento de práticas educativas e educacionais vinculadas ao cotidiano, à cultura e à alternância que possam favorecer a fixação do homem em seu local de origem, diminuindo o êxodo rural e a hipertrofia das cidades.

A escola do meio rural surgiu muito tarde e por conta disso ainda é perceptível a precariedade e um olhar voltado para a 'marginalidade', no que tange ao seu funcionamento e à definição de diretrizes políticas e pedagógicas que regulamentem sua organização. A educação rural, desde o seu surgimento, conforme Almeida (2005), centra-se num modelo de educação urbana. Sabemos que o 
problema da educação não está localizado apenas no meio rural, mas compreendemos que nele a situação é mais grave, tendo em vista que alguns princípios e políticas, voltados historicamente para a educação rural, são centrados na lógica urbana e transpostos para a escola rural, desconsiderando-se seu contexto e a cultura local.

Sabemos que são mínimas as leituras que dão subsídios teóricos e apontam para as necessidades básicas do meio rural, por isso as possíveis soluções para os problemas desse meio e que envolvem, em parte, a educação são simplesmente ignoradas. Historicamente, presenciou-se no território rural uma educação desprestigiada, em que se escolhe o professor não pelo perfil, formação ou competência, mas por sua atuação política. Assim, percebemos que há um descaso quanto à formação, à identidade, aos saberes e às práticas pedagógicas dos professores da zona rural.

A Lei n 9.394/96 (BRASIL, 1996), que estabelece as Diretrizes e Bases da Educação Nacional, propõe medidas de adequação da escola à vida no meio rural; diretrizes operacionais que confiram alteridade e respeito às suas peculiaridades; a construção de uma escola voltada para o povo rural, sendo regulamentada por meio de estratégias específicas para o atendimento escolar. A mesma lei também deixa claro que a formação dos profissionais da educação ocorra tanto em nível de formação inicial quanto continuada, e que a qualidade do ensino no campo possa ser preservada e garantida com investimentos financeiros e políticos contextualizados ao território rural.

Nas escolas rurais de Itapetinga, as classes são multisseriadas, atendendo numa única sala de aula a alunos de várias séries (pré-escolar a $4^{\mathrm{a}}$ série). Por isso, estima-se ser necessário que os professores que nelas atuam tenham uma formação bem delineada, para que possam lidar com a diversidade existente. Neste aspecto, a educação rural, no bojo de sua implantação tardia e descontínua, ainda carrega marcas de sua criação precária, mas com alguns avanços. Assim, os êxitos e fracassos da escola rural ainda não são totalmente conhecidos nem relacionados com as suas causas. Dessa forma, entende-se que muitas coisas devem mudar na educação rural, sendo a mais urgente a formação dos professores. Assim, acredita-se que a relação dos saberes dos professores, a prática pedagógica e a (re)construção das identidades são eixos norteadores da formação e do trabalho docente.

$\mathrm{O}$ trabalho dos professores rurais baseia-se nos postulados de que a cultura e a diversidade fazem parte do seu cotidiano, considerando-se a realidade das classes multisseriadas e as exigências postas no âmbito do trabalho docente como elementos que interferem tanto no processo de formação dos professores, quanto na prática educativa e no processo de desenvolvimento e aprendizagem dos alunos.

\section{Profissão docente e a professora' rural: apontando algumas questões históri- cas}

Evidencia-se que é na configuração da profissão que a identidade profissional é construída. Para Nóvoa (1992), a profissão docente surge no seio de algumas congregações religiosas, por volta do século XVI, quando, nesse período, a Igreja detinha a hegemonia política, cultural e religiosa.

Com a crescente intervenção do Estado na Educação (século XVIII), passou a haver uma maior atenção aos professores, instituindo-os como corpo profissional. Criaram-se neste processo as escolas normais, em pleno século XIX, o que trouxe como uma das consequências importantes o fortalecimento inicial da profissão docente.

No contexto da profissionalização do professorado, exercia-se a profissão docente por tempo integral (ou como atividade principal), e para continuar o desenvolvimento do exercício estabeleceuse como necessário um suporte legal emitido pelo Estado, ou seja, uma licença para ensinar.

As reflexões sobre a feminização do magistério (NÓVOA, 1992) ganham destaque na segunda metade do século XIX, marcando a profissão docente com o embate entre a profissionalização, menosprezo da profissão e proletarização do trabalho docente, tendo em vista que, historicamente, a mulher era apenas responsável pelos cuidados com os filhos e com o marido. Não só no campo da educação, mas também em outros, como a lite-

\footnotetext{
Optou-se no texto por utilizar o gênero feminino quando nos referimos a "professora", em razão da constituição do quadro docente das profissionais que atuam nas escolas rurais, mais especificamente, no território rural de Itapetinga, contexto da presente pesquisa.
} 
ratura, a música e a dança, observa-se a condição de subordinação e repressão das mulheres em relação ao poder masculino, isto até o início do século XX, quando a mulher exercia uma função social vinculada ao espaço doméstico, privado. Foi nesse processo histórico que a mulher, pouco a pouco, profissionalizou-se, e ampliaram-se as possibilidades de participar ativamente de processos identitários. Nessa trajetória, o principal papel profissional exercido pela mulher foi o de professora, formando-se no curso de magistério e exercendo a função de "tia"'. Assim, a identidade profissional feminina foi sendo construída, baseada na inserção feminina no mercado de trabalho, mesmo que exercendo a docência, permitindo conquistar um espaço na vida pública. Segundo Louro:

A entrada das mulheres no exercício do magistério - o que, no Brasil, se dá ao longo do século XIX (a princípio lentamente, depois de forma assustadoramente forte) - foi acompanhada pela ampliação da escolarização a outros grupos ou, mais especialmente, pela entrada das meninas na sala de aula (2003, p. 78).

Em seguida, com a feminização do magistério, a profissão passou a viver um processo de desprofíssionalização (NÓVOA, 1992). No meio rural, a desprofíssionalização docente sempre existiu, principalmente quando se situa a professora leiga na história, mais comum nas áreas rurais. Nesse aspecto, ela desempenha um importante papel quando possibilita a escolarização no meio rural, pois, segundo Therrien, "a professora leiga é inseparável do processo de construção social da escola do meio rural" (1991, p. 23). Sobre essa questão, Therrien (1993, p. 44) continua afirmando que:

\section{[...] a professora rural é gerada pela estrutura social do seu contexto de vida (que é também nacional), é a partir dessa mesma estrutura que se deve conceber estratégias de construção da identidade pedagógica dessa professora, situando-a no movimento de cons- trução social da escola do trabalhador.}

A presença de questões vinculadas à construção da identidade profissional e de gênero feminino na carreira do magistério, tanto na década de 1990

${ }^{2}$ A concepção aqui utilizada relaciona-se à vinculação das mulheres ao magistério primário, hoje Ensino Fundamental, como uma atividade que se associava à continuidade das funções maternas e familiares. quanto nos dias atuais, se confirma principalmente quando se verifica que dos professores que atuaram nas escolas rurais do município de Itapetinga, de 1975 a 2008, apenas sete foram do sexo masculino. O gênero constitui-se como uma importante marca da carreira do magistério, principalmente na zona rural, pois, historicamente, as mulheres trabalhadoras camponesas que sabiam ler e escrever se tornavam professoras nas suas comunidades, dando continuidade à história da escola rural. A professora, mulher, no meio rural, sempre foi mais comum que o homem, delineando essa profissão, nos século passado e no presente século, como feminina. Assim, é valido ressaltar que a essas mulheres professoras sempre faltaram muitas coisas para desenvolverem o trabalho docente, como formação, condições de realização do trabalho pedagógico, material didático etc. Destaca-se o fato de, historicamente, percebermos que a elas restou o recebimento dos piores salários e o seu papel social, na comunidade em que a escola está inserida, nunca ter sido valorizado. $\mathrm{O}$ fato de serem mulheres trabalhadoras, moradoras da região (muitas vezes), que sabiam ler e escrever, facilitava a entrada no magistério como professora leiga.

Com o passar dos anos, alguns problemas ainda permanecem no meio rural, como o do transporte escolar para alunos e professores, o recebimento dos piores salários por parte dos professores, a carência de contratação de merendeiras e pessoal de apoio, o investimento inicial na formação dos professores etc. Torna-se necessário tentar superálos. Contudo, mais que superar é preciso compreender que a realidade do sistema educacional rural é decorrente de um sistema político, econômico, cultural e educativo marcado por problemas que ainda existem, para que as soluções possam ser pensadas e buscadas, e que elas sejam compatíveis com o contexto em questão (THERRIEN, 1991).

Pensar a educação rural implica refletir também sobre o sistema político-econômico em que as demandas educativas são geradas; mais que isso, implica contextualizá-las no âmbito do sistema cultural de diversificação que precisa/ deve ser valorizado e, para tanto, carece de uma conjuntura pedagógica para tal concretização. Por isso, pensar a educação rural implica investir na formação e profissionalização de seus professores: 
Quem são? Quais os seus saberes, sua formação, sua identidade e como desenvolvem suas práticas pedagógicas? Só quando responderem-se essas perguntas compreender-se-á a realidade de que se está falando e suas discrepâncias. Assim, os professores configuram-se como importantes no contexto educacional e desempenham papel fundamental na construção de práticas de intervenção social e de dinamismo local.

\section{Professoras rurais: quem são?}

Intenta-se aqui sistematizar algumas reflexões sobre o trabalho realizado com professores rurais, com base nas entrevistas narrativas e na análise das suas histórias de vida. Busca-se apresentar contribuições importantes para a formação e para a reflexão sobre a prática pedagógica por meio de entrevistas narrativas, e possibilitar a reconstituição de uma história que permita o entendimento de si mesmo como pessoa e profissional. Por isso, acredita-se que o trabalho centrado na memória de formação permite descobertas importantes sobre a prática docente e questões vinculadas à vida profissional.

A recuperação do eu, conforme Souza (2007), marca um olhar sobre si em diferentes espaços e tempos, possibilitando articulações das lembranças com as narrativas das experiências, ao destacar que "narrar é enunciar uma experiência particular refletida sobre a qual construímos um sentido e damos um significado" (p. 144). Nessa perspectiva, adotaramse princípios da abordagem (auto)biográfica como método de pesquisa, baseados nas histórias de vida, por entender-se que se configura num processo de conhecimento de si, no qual é possível conhecerse como pessoa e como profissional. A narrativa vincula-se às experiências e aprendizagens que os sujeitos constroem ao longo da vida, com base nos percursos e trajetórias de vida-formação. Segundo Araújo e Almeida (2005, p. 4),

Sendo a experiência vivida e refletida uma forma de reordenar conhecimentos, essa experiência tem na narrativa a sua condição operativa e multiplicadora. [...] Tudo que não é narrado morre com o sujeito. Ao contrário, tudo que é narrado e partilhado pode se constituir em elemento potencializador de novas sínteses criativas e em elos que ligam os sujeitos entre si. Dessa perspectiva, experiência e narrativa são pares indissociáveis do conhecimento e da cultura.

Na narrativa, o conhecimento possibilita ao professor (auto)avaliar-se e refletir sobre a sua história de vida. A cultura pode ser a sua e a dos outros, e esses outros podem ser aqui entendidos como os alunos e os povos da zona rural, por exemplo. O conhecimento da cultura e do contexto em que os alunos vivem implica-se na prática, na formação, na identidade e nos saberes dos professores, possibilitando-lhes vínculos com a comunidade. O professor que aceita e ensina de acordo com a cultura dos seus alunos, refletindo sobre formação, identidade, saberes e práticas, tem melhor condição de pensar sobre o processo educativo e deixar sua prática pedagógica tornar-se prática de formação. No Quadro 1 está exposto o perfil de algumas professoras colaboradoras da pesquisa.

\begin{tabular}{|l|l|l|l|l|l|l|l|}
\hline Professora & Idade & $\begin{array}{l}\text { Estado } \\
\text { civil }\end{array}$ & Filhos & Formação & $\begin{array}{l}\text { Tempo que } \\
\text { atua como } \\
\text { professora }\end{array}$ & $\begin{array}{l}\text { Tempo } \\
\text { que atua } \\
\text { na zona } \\
\text { rural }\end{array}$ & $\begin{array}{l}\text { Situação } \\
\text { funcional }\end{array}$ \\
\hline Estrela & 43 & casada & 2 & Especialista & 12 anos & 09 anos & Efetiva \\
\hline Géssica & 45 & viúva & 2 & Graduanda & 15 anos & 10 anos & Efetiva \\
\hline Yasmin & 33 & casada & 2 & Graduanda & 06 anos & 06 anos & Contratada \\
\hline Keli & 41 & casada & 1 & Graduanda & 12 anos & 08 anos & Contratada \\
\hline Leci & 41 & casada & 2 & Graduanda & 17 anos & 17 anos & Contratada \\
\hline
\end{tabular}

Quadro 1. Perfil das professoras colaboradoras

Fonte: Pesquisa de Campo - Perfil das colaboradoras (2008).

(1): Nomes fictícios escolhidos pelas professoras para serem identificadas na pesquisa. Foi solicitado às mesmas que escolhessem um nome que tivesse sentido e significado para elas. 
Coincide, aqui, o fato de todas as professoras que atuaram na década de 1990 terem iniciado a carreira do magistério numa escola rural no município de Itapetinga. Todas adquiriram o título de professora mediante conclusão do curso de magistério, entre a década de 1980 e início da década de 1990 na mesma escola em Itapetinga (Centro Educacional Alfredo Dutra).

Do ano de 1975 a 2008 foi identificado o cadastramento de 49 escolas rurais nesse município, mas durante o ano de 2008 apenas 14 estavam em funcionamento. Não há na secretaria das escolas rurais registros anteriores a 1975. As escolas, palco da primeira experiência das professoras Keli e Leci $^{3}$, estão hoje desativadas.

A questão de formação de professores deu uma melhora, deu um avanço por conta de que eu, eu mesmo fui beneficiada com essa formação de professores. Porque na década de 90 lembro de que tinha umas duas colegas que era, eram leigas. Elas ficava até acanhada de participar muito, de muitas vezes até um colega saber a respeito da vida delas. Mas a gente sabia por conta de um ou outro alguns comentários, mas existia professores leigos e hoje não mais existe (Depoimento de Keli).

A formação de professores dá-se apoiada na existencialidade, e é um processo que ocorre durante toda a vida, mas em se tratando da formação institucionalizada, espaço-temporal, é válido afirmar que as professoras pesquisadas, na década de 1990, eram professoras diplomadas em nível médio. Entretanto é identificada nesse período a presença de professores leigos, que hoje já não existem mais na região. Diferentemente do que acontece em outras regiões do estado.

$\mathrm{O}$ fato de a professora Estrela ter sido, no presente século, a primeira professora da zona rural a ter nível superior foi destacado na fala das professoras Keli e Yasmin, quando se referiam às questões acerca de como trabalhar com um projeto, por exemplo, que para ela, que já tinha nível superior em Pedagogia desde 2006, com certeza era mais

\footnotetext{
Os nomes aqui utilizados são fictícios e foram escolhidos pelas professoras para serem identificadas na pesquisa. Solicitou-se às mesmas que escolhessem um nome que tivesse sentido e significado na suas histórias de vida-formação. Os excertos utilizados no texto foram produzidos no contexto de formação e da pesquisa desenvolvida. Mantivemos as transcrições com vícios de linguagem, por respeitar as narrativas e modos de expressão das entrevistadas.
}

fácil. O nível superior na zona rural constituiu-se um diferencial, colocando a professora num lugar de destaque, o que foi aumentando quando ela ingressou na especialização. As outras professoras cursavam o Curso Normal Superior, desde 2006, num projeto de formação de professores desenvolvido entre a Prefeitura Municipal de Itapetinga e a Universidade Estadual do Sudoeste da Bahia, permitindo a outras professoras que não eram efetivas terem o nível superior. $\mathrm{O}$ excerto da entrevista de Keli destaca algumas questões sobre a formação, quando afirma que:

Tem professores, é, que já concluíram o $2^{\circ}$ grau, mais curso superior como também tivemos colegas que já tinha feito o curso superior. Então esse ano de 2005 já deu um avanço, inclusive fomos previlegiado com o curso superior né. Esse curso superior foi uma seleção de professores que já estavam trabalhando na rede, que o prefeito, ele, ele fez esse, ele fez esse, ele fez essa qualificação pra o professor, concluindo, é, tendo 3 anos, concluímos em 3 anos por conta de que a carga horária maior e o tempo menor. Então nós chegamos a concluir em 3 anos por conta da carga horária que é maior (Depoimento de Keli).

Quanto à formação dos professores do meio rural e à política que permeia a formação, uma professora da década de 1990 relata que:

\begin{abstract}
Mudou, mudou muito porque os professores no meio rural hoje estão capacitados sempre procurando estudar mais e aprender mais não tem aquele negócio de no meio rural tem que ser um professor, qualquer professor não, não tem isso mas não. Professor se ele tiver curso superior e ele for chamado para o meio rural e ele aceitar a vaga ele vai pra o meio rural. Se for tirar um professor do meio rural e colocar outro, for tirar aquele que tem curso e colocar o que não tem curso porque no meio rural pode ir qualquer um, não existe isso não (Depoimento de Géssica).
\end{abstract}

O acúmulo de funções por parte dos professores perpassa as questões da educação rural, o que constitui ainda um problema atual. Sobre essa questão, Santana, Leite e Pinto afirmam que "no meio rural, também o professor acumula diversas funções, pois 'ser professor rural significa quase sempre exercer funções de outros profissionais: secretário escolar, bibliotecário, enfermeiro, merendeira, servente e outros"” $(1989$, p. 28). Não é comum, na trajetória das professoras, elas atuarem como merendeiras. 
Apenas as professoras que moravam na fazenda e não encontravam apoio deveriam atuar como merendeiras, mas, independente da merenda, reconhecem que são mais que professoras, quando afirmam:

Na década de 90, a questan de merendeira, desde quando eu iniciei sempre tinha uma mãe que apoiava, dava um apoio né. Não que era assim merendeira, mas sempre alguém próximo da escola, esse alguém deveria ser alguma mãe que sempre tinha algum filho na escola. Então era uma forma assim de ajudar a escola e com essa ajuda ela ganhava uma ajuda de custo que não era um salário, era uma ajuda de custo sempre inferior ao salário. Ajuda de custo mesmo que por ela ajudar na, a fazer a merenda, na limpeza da escola, então a prefeitura, é, estipulava, tinha um valor pra cada merendeira. [...]. E ai o professor tem que cê o professor de, dinâmico, dinâmico, que tem que pensar em tudo, pensar na parte sentimental, tem que pensar, é, na parte psicológica, na parte de ser mãe, de ser professor, de ser tia, de ser tudo (Depoimento de Keli).

Dá, porque aqui a gente é o diretor, a gente é o professor. De tudo a gente faz um pouco. Temos uma pessoa que nos auxilia, porém essa pessoa não ganha o suficiente pra fazer essas funções, mas aqui na minha escola mesmo é uma pessoa que não reclama, está sempre pronta pra poder me ajudar. [...]. Ainda a gente encontra dificuldade aqui pra trabalhar na zona rural, por ser um professor só, como eu falei, a gente acaba sendo diretor, a gente é o professor, a gente é o conselheiro (Depoimento de Yasmin).

A política salarial dos professores também diferenciava os valores recebidos por professores leigos e diplomados. Segundo Teles (1989), em pesquisa realizada em 1986, na Bahia, a diferença de salário de um professor leigo para um professor titulado era de cerca de 30\%. Alencar (1993) também discute essa perspectiva salarial e fala sobre essa mesma diferença de salário - o mesmo percentual - entre os professores no Estado do Ceará, em pesquisa realizada em 1987, ressaltando que as professoras leigas ocupam o nível mais baixo na grade salarial da municipalidade. Em Itapetinga, na década de 1990, não havia diferença de salário entre professores diplomados e leigos. A diferença hoje encontrada refere-se ao fato de trabalharem na zona rural e ganharem uma gratificação a mais pelo seu trabalho, conforme relato de uma professora:
Uma outra conquista foi a questão do professor da zona rural ganhar um pouquinho a mais, uma percentagem. Ganhar auxilio alimentação, os professores que moram na zona rural ganham auxilio alimentação que não tinha (Depoimento de Estrela).

O fato de muitas escolas serem longe da sede do município obrigava alguns professores a morar na escola. Até hoje é assim, mas antes não havia auxílio alimentação. Para as escolas mais próximas, hoje existe o transporte, carros que levam e trazem todos os dias e ainda um percentual a mais no salário, por atuarem na zona rural. Para as professoras que moram nas escolas, existe o carro que as leva na segunda-feira e as pega na sexta-feira. Contudo, essa questão do transporte foi uma conquista de anos, pois antes as professores deslocavam-se por meio de caronas e cavalos para chegarem até as escolas.

Tudo que nós conseguimos ou que nós temos de mudança na zona rural, como por exemplo, a incorporação do salário, há mais professoras no meio rural, a questão do transporte pra levar e buscar o professor, tudo isso foram conquistas dos professores. Foram os professores que pediu, os professores que buscaram, os professores que lutaram. Todos (Depoimento de Estrela).

No processo das entrevistas narrativas, muitas professoras falaram sobre as experiências em relação as transporte escolar, a estrutura física das escolas e também acerca de questões pedagógicas e financeiras vinculadas ao trabalho docente. Evidencia-se que a estrutura pedagógica, segundo os relatos, não atende desde a década de 1990 até os dias atuais, pois a figura do coordenador pedagógico já existia desde o final do século $\mathrm{XX}$, mas sempre foi ausente no cumprimento das suas funções. Inexiste, por parte da coordenação pedagógica, a ajuda necessária para o desenvolvimento do trabalho pedagógico em classes multisseriadas, o que se configura como uma das dificuldades relatadas pelas professoras que atuam no meio rural.

Falta pra gente um apoio pedagógico em termos do planejamento. Eu acho que a zona rural deveria ter coordenadores que nos auxiliasse porque o trabalho da zona rural é um trabalho muito complicado, é um trabalho muito dificil que exige muito do professor, 
e dentre esse trabalho uma das maiores dificuldades que eu encontro é alfabetizar o aluno na escola da zona rural porque alfabetizar já é um processo difícil, já é um processo complicado pra o professor (Depoimento de Yasmin).

Quanto à estrutura física, algumas escolas ainda funcionam em antigas casas de trabalhadores das fazendas, que foram cedidas e adaptadas, deixando a desejar, muitas vezes, por causa de pequenos detalhes (reformas inacabadas ou mal feitas, quadro de giz muito desgastado, falta de pátio para os alunos brincarem, salas pequenas e apertadas etc.). Algumas outras escolas são prédios escolares construídos pela prefeitura. Entretanto, em geral, ainda que insuficientes muitas vezes, todas as escolas têm boa estrutura física e já mudaram no decorrer dos anos. Historicamente, é sabido que as condições de trabalho e material didático nunca foram favoráveis no/ao meio rural.

Na verdade as escolas da zona rural, que que as escolas da zona rural tem? Uma sala, um prédio, com as paredes com as cadeiras dentro com uns armários velhos, que nós recebemos só coisas velhas, nós nunca recebemos coisas novas. Coisas que da zona rural, da zona urbana, por exemplo, não vai mais servindo, vai sendo mandada pras escolas da zona rural. Pra você ter uma idéia nós não temos um armário novo nas escolas da zona rural. O professor não tem um armário pra guardar seus material quando ele chega na zona rural. Ainda existe um monte de coisa que a gente precisa superar, a gente precisa conquistar na zona rural. Que é sobre material didático, sobre, nosso material didático, por exemplo, ele não é elaborado pra zona rural é o mesmo material didático que é dado na zona urbana é passado pra zona rural. E não dá certo (Depoimento de Estrela).

As professoras disseram mobilizar a mudança, buscar as mudanças, e, conforme relatos, as mudanças já vêm acontecendo. Muitas coisas ainda precisam ser superadas, mas as reivindicações e as lutas das professoras já vêm dando resultados. Ainda falta a valorização das diferenças; falta à elite governamental perceber a unidade na diversidade (NICOLAU, 1991) e valorizá-la. Perceber que, da zona urbana para a zona rural, há uma enorme diferença que deve ser vista e considerada na busca e na proposição de melhorias. Conforme Santana,
Leite e Pinto, "antes de implantar qualquer tipo de assistência à educação rural, seria necessário definir que tipo de educação se pretende para o meio rural, [...] proporcionando uma educação voltada para as suas necessidades e interesses reais [...]" (1989, p.30). É preciso fazer uma análise crítica da realidade rural e adaptar a escola à realidade dos seus alunos, sendo feita para eles e com a sua participação.

A educação rural precisa ser pensada com a participação de sujeitos de vivências e práticas rurais, sujeitos esses que conhecem suas reais necessidades. As mudanças precisam ser buscadas e devem mesmo acontecer no meio rural. E o professor, como profissional que trilha o caminho da mudança e das incertezas, deve ser formado de maneira que adquira conhecimentos pedagógicos comuns, especializados e habilidades específicas para contribuir com isso.

Nesse percurso histórico, a professora rural, na maioria das vezes leiga, fez história, e em muitos lugares essa história continua sendo construída. Em alguns lugares ainda encontra-se muitos desses professores com o ensino fundamental incompleto, assim como já temos professores que atuam no meio rural com uma formação em nível superior, o que certamente vem fazendo diferença. Entretanto esse não é o único elemento a promover a diferença. A professora do meio rural não precisa, para promover um ensino melhor, somente de uma melhor formação ou de frutos de políticas públicas; ela precisa identificar-se com o contexto em que atua. É fundamental pensar a educação rural tomando-se por base as reais necessidades dos povos rurais, e nesse processo de mudança da educação o professor torna-se agente de transformação.

Por isso, torna-se relevante que o professor identifique-se com a escola rural, reflita sobre o seu processo de formação, busque uma formação com base nas experiências práticas do contexto em que está atuando, deixando que as experiências práticas sejam delineadoras por novos saberes e, consequentemente, de uma nova identidade. Identidade essa que vai sendo desvelada ao longo das vivências.

Este trabalho buscou ressaltar a importância da escuta da voz de professoras rurais, possibilitando às mesmas narrarem suas histórias de vida pessoal e 
profissional e rememorarem episódios importantes que fazem parte da história da profissão docente e da educação rural. As narrativas evidenciam percursos e trajetórias que compõem a história da educação rural em Itapetinga (BA), ao destacar vários elementos do contexto educacional rural baseados nas buscas de melhorias, sofrendo mudanças de um século para o outro. Ainda assim, a invisibilidade social, nesse contexto, perdura até os dias de hoje, não só nesse município, mas em vários espaços do território brasileiro, impedindo que as mudanças cheguem, de fato, com rapidez, precisão e sem lutas. Foi possível aqui conhecer a história de mulheres professoras e dimensões históricas de um contexto e de uma profissão em desenvolvimento e em processo de formação.

\section{REFERÊNCIAS}

ALENCAR, J. F. A professora "leiga": um rosto de várias faces. In: THERRIEN, J; DAMASCENO, M. N (Orgs.). Educação e escola no campo. Campinas: Papirus, 1993. p. 177-190.

ALMEIDA, D. B. A educação rural como processo civilizador. In: STEPHANOU, M; BASTOS, M. H. C. (Orgs.). Histórias e memórias da educação no Brasil: Século XX. Petrópolis: Vozes, 2005. v. 3, p. 278-295.

ARAÚJO, M. F.; ALMEIDA, M. C. X. Narrativas de vida e formação do sujeito. In: ENCONTRO DE PESQUISA EDUCACIONAL DO NORTE NORDESTE, 17., Belém, 2005. Anais... Belém, 2005. p. 1-9.

BRASIL. Lei no 9.394, de 20 de dezembro de 1996. Lei de Diretrizes e Bases da Educação Nacional. Estabelece as Diretrizes e Bases da Educação Nacional. Diário Oficial [da] República Federativa do Brasil, Poder Executivo, Brasília, DF, 23 dez. 1996. Seção 1, p. 27833.

LOURO, G. L. Gênero e magistério: identidade, história, representação. In: CATANI, D.B. et al (Orgs.). Docência, memória e gênero: estudos sobre formação. São Paulo: Escrituras, 2003. p.75-84.

NICOLAU, M. L. M. O professor leigo: institucionalizar ou erradicar? In: BRASIL, Ministério da Educação. Secretaria Nacional de Educação Básica. Professor leigo: institucionalizar ou erradicar? São Paulo: Cortez; Brasília: SENEB, 1991. p. 27-36.

NÓVOA, A. O passado e o presente dos professores. In: 1992. p. 13-34.

(Org.). Profissão professor. 2 ed. Lisboa: Porto,

PETTY, M.; TOBIM, A.; VERA, R. Uma alternativa de educação rural. In. WERTHEIN, J.; BORDENAVE, J. D. Educação rural no terceiro mundo: experiências e novas alternativas. 2. ed. Rio de Janeiro: Paz e Terra, 1981. p. 31-63.

SANTANA, M. N. C.; LEITE, C. G.; PINTO, M. L. L. C. Remuneração do professor leigo. In: LUZ, A. M. C. et. al. O professor leigo. Cadernos de Educação Política, Salvador, Universidade Federal da Bahia/Ianamá, 1989. p. 27-31.

SILVA, I. R. T. A escola primária rural. Porto Alegre: Globo, 1952.

SOUZA, E. C. (Auto)biografia: histórias de vida e prática de formação. In: NASCIMENTO, A. D.; HETKOWSKI, T. M. (Orgs). Memória e formação de professores. Salvador: EDUFBA, 2007. p. 59-74.

TELES, J. F. S. O professor leigo e outros problemas do ensino municipal. In: LUZ, A. M. C. et. al. O professor leigo. Cadernos de Educação Política, Salvador, Universidade Federal da Bahia/Ianamá, 1989. p. 11-26.

THERRIEN, J. A. A "professora” leiga e o saber social. In: BRASIL, Ministério da Educação. Secretaria Nacional de Educação Básica. Professor leigo: institucionalizar ou erradicar? São Paulo: Cortez; Brasília: SENEB, 1991. p. 13-25.

. A professora rural: o saber de sua prática social na esfera da construção social da escola no campo. In: THERRIEN, J.; DAMASCENO, M.N (Orgs.). Educação e escola no campo. Campinas: Papirus, 1993. p. 44-51. 